\title{
A vênus aberta de Angélica Liddell: uma abordagem do espetáculo ¿Qué haré yo con esta espada? (Aproximación a la leyy al problema de la belleza)
}

DANIELE ÁVILA SMALL

Título: ¿Qué haré yo con esta espada? (Aproximación a la ley y al problema de la belleza). Texto, direcção, cenografia e figurinos: Angélica Liddell. Interpretação: Victoria Aime, Louise Arcangioli, Paola Cabello Schoenmakers, Sarah Cabello Schoenmakers, Lola Cordón, Marie Delgado Trujillo, Greta García, Masanori Kikuzawa, Angélica Liddell, Gumersindo Puche, Estíbaliz Racionero Balsera, Ichiro Sugae, Kazan Tachimoto, Irie Taira e Lucía Yenes. Desenho de luz: Carlos Marquerie. Desenho de som: Antonio Navarro. Local e data de apresentação: Teatro Sesc Santos, Brasil, Mirada - Festival Ibero-Americano de Artes Cénicas de Santos, 12 de Setembro de 2016.

Las mujeres desnudas somos como los muertos: nadie puede dejar de mirarnos.

ANGÉLICA LIDDELL

Escrever sobre a obra mais recente de Angélica Liddell é um exercício crítico no sentido amplo. O título, ¿Qué haré yo con esta espada? (Aproximación a la ley y al problema de la belleza) é um convite ao pensamento. Depois de assistir duas vezes ao espetáculo, no Mirada-Festival Ibero-Americano de Teatro de Santos e no Sesc Pinheiros, na cidade de São Paulo, Brasil, em setembro de 2016, parece que a abordagem crítica mais possível para esta peça é a que dá continuidade à reflexão sobre as suas questões filosóficas.

A peça pode ser analisada de diversos pontos de partida, pois, em cerca de quatro horas de duração, oferece abordagens diversas para os assuntos propostos, como cenas de dança, monólogos proferidos frontalmente, narrativas simbólicas que dariam um prato cheio para os semióticos, narrativas do real e projeção de imagens factuais. Uma abordagem totalizante, no entanto, deixaria de fora o gesto crítico do corte.

$\mathrm{O}$ espetáculo parte de dois fatos terríveis que se deram na cidade de Paris. Em 1981, o estudante japonês Issei Sagawa - que hoje está vivo, livre e dando entrevistas - matou, estuprou, desmembrou e comeu a carne de sua 


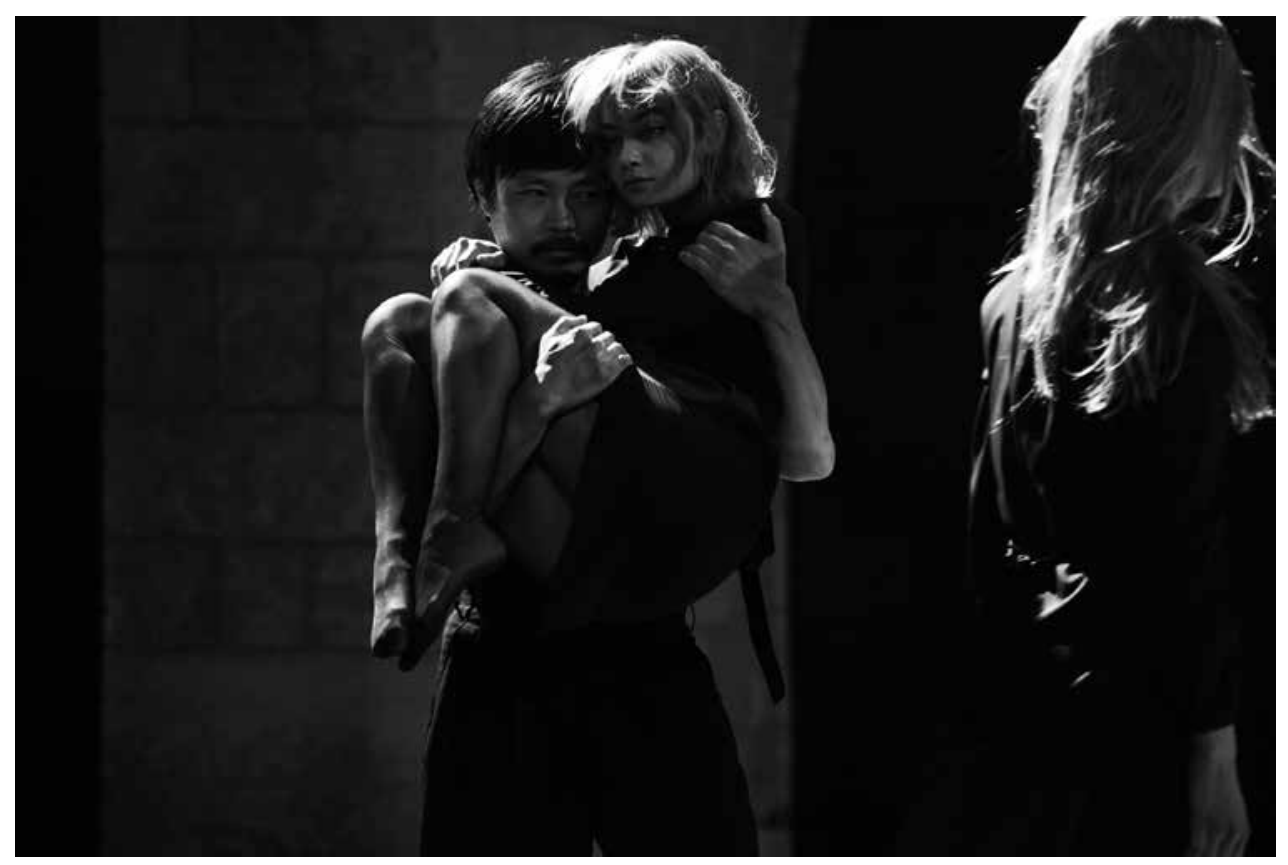

¿QUÉ HARÉ YO CON ESTA ESPADA? (APROXIMACIÓN A LA LEY AL PROBLEMA DE LA BELLEZA), DE ANGELICA LIDDELL, 2016, [F] LUCA DEL PIA

colega holandesa Renée Hartevelt, abandonando o corpo em duas malas no Bois de Bologne. Em 2015, um ataque terrorista deixou mortos e feridos em diferentes pontos da cidade, em maior número no Bataclan, casa de shows que recebia, naquela noite, a banda norte-americana Eagles of Death Metal - e a abordagem desse episódio no espetáculo merece um texto à parte. Na lida com essas duas situações, o espetáculo me apresentou um redesenho de Paris, colocando a cidade no meu mapa de afetos e experiências de modo incomum.

O ponto de partida da obra é o impacto desses dois acontecimentos sobre Liddell, o processo de assimilação da violência dos fatos tendo em vista a imagem ideal de Paris, um símbolo da beleza, da arte (das Belas-Artes, sobretudo), da alta cultura e da civilização ocidental. Nesses acontecimentos, a beleza e a arte são alvos de violência em diferentes instâncias. Há o ataque à beleza clássica do corpo feminino e à beleza da cidade, além do ataque à arte - representada pela agressão aos espectadores de um show de rock, uma forma de arte associada à ideia de liberdade da juventude ocidental.

A linguagem do espetáculo, que oscila entre registros narrativos, líricos, míticos, cerimoniais e ritualísticos, revela o caráter obsessivo do pensamento quando se propõe a enfrentar um problema, lançando 


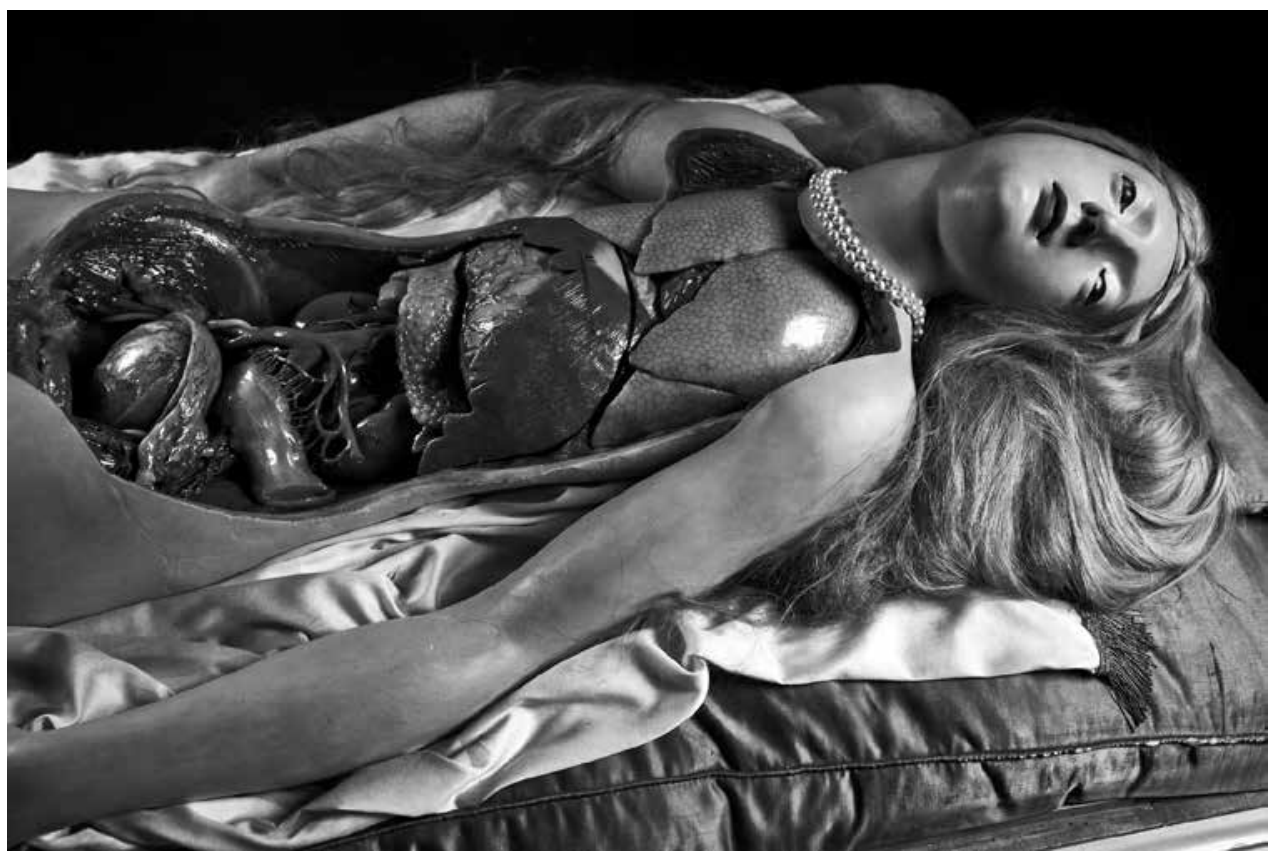

DETALHE DE UMA DAS ESTÁTUAS DE CLEMENT SUSINI

mão de repetições, excessos, movimentos contínuos em longa duração, descontinuações, processos endógenos e momentos catárticos. Liddell concentra no próprio corpo os momentos mais discursivos, fazendo acontecer seu embate intelectual no espaço e no tempo do corpo, saturando a fala com a energia da respiração e do movimento, do trabalho concreto sobre a materialidade do seu elemento cênico mais contundente, o cerne da sua obra.

Mas foi uma narrativa do real que conduziu a minha relação com a obra. Uma narrativa do real e uma referência externa ao espetáculo, unidas pela forma como essa narrativa é posta em cena, com o acúmulo das imagens da peça. A predileção de Issei Sagawa por moças europeias, brancas e delicadas, de cabelos e olhos claros, a presença no espetáculo de meninas nesse perfil, como se fossem figuras de Botticelli, a narrativa minuciosa dos cortes perpetrados contra o corpo da vítima e as imagens desse corpo aberto em uma mesa de autópsia, projetadas na cena, conduziram a minha reflexão a uma relação inevitável com Ouvrir Vénus: Nudité, rêve, cruauté, de Georges Didi-Huberman.

Ele estuda o nu feminino em quadros de Botticelli, como $O$ Nascimento de Vênus e os painéis de História de Nastagio degli Onesti, a partir de uma operação anacrônica, olhando para o humanismo renascentista do pintor 
italiano a partir de artistas modernos como Marquês de Sade e Georges Bataille. Com Nietzsche, Warburg e Freud, e partindo da relação dialética entre a forma clássica e o disforme, a forma amorfa que aparece em Sade e Bataille, ele conclui suas ideias com as estátuas de cera de Clement Susini, expostas em um gabinete de anatomia no La Specola Museu de História Natural em Florença. Ele analisa o processo psíquico do ser humano diante do nu, bem como a relação intrínseca entre violência, beleza e arte, chamando atenção para o fato de que o processo psíquico mesmo, com seus contrastes intrínsecos, é o objeto central da mimese artística.

Os painéis que compõem História de Nastagio degli Onesti apresentam uma «ficção moralizante», que pretende ensinar as mulheres que a atitude dura e insensível diante do desejo masculino pode não acabar bem para elas. Um homem convence uma moça a se casar com ele contando a história de uma visão, na qual um cavaleiro persegue uma mulher nua em um bosque, rasga a sua carne com uma espada, abre o seu corpo, retira parte de seus órgãos e dá de comer a um cão. Em Botticelli, portanto, a arte é um meio de instrumentalização moral e afirmação de culpa da mulher por toda violência sofrida.

Sobre as esculturas de cera de Susini, Didi-Huberman chama atenção para a beleza das estátuas, tendo em vista a descrição feita por Sade em seu Viagens à Itália. Ele repara no seu ilusionismo perverso, nos olhos de vidro, cabelos naturais, pelos pubianos, bem como na pose lânguida e sensual das estátuas. Tudo nessa Vênus da medicina é apelo ao toque. Ela «pede para ser tocada» e «pede para ser aberta». Ele vê nessas estátuas uma tensão inconciliável, a convivência do horror e da beleza, a revelação do desejo humano de abertura do envelope corporal, uma curiosidade violenta de rasgar e desfigurar a beleza, de explodir a harmonia.

A encenação do relato de Sagawa, amparada por uma atmosfera cerimonial, desloca a narrativa do mundo dos homens para uma esfera mítica. A musicalidade da fala do ator em língua japonesa alcança uma sonoridade ritualística - para o público ocidental. Não é só a descrição do desmembramento de Hartevelt que nos dá imagens do disforme, mas também o conteúdo mesmo da fala do assassino, a exposição do seu desejo, da sua curiosidade, na primeira pessoa. Essas imagens do disforme, tão intensas em uma fala tão deslocada de uma ideia humanista de humanidade, entram em uma categoria de arte e beleza que escapam à moral e à lei dos homens. Em contraste com a pintura de Botticcelli, o espetáculo aciona uma chave de anulação da perspetiva moralizante. 
Essa anulação oscila na medida do nosso distanciamento e da nossa adesão à curiosidade, sobretudo diante das projeções das imagens reais do cadáver desmembrado. Não sem um grave mal-estar.

O desejo canibal é a ânsia da carne. Sagawa não deseja a superfície, nem a penetração temporária: sua obsessão não é simplesmente sexual. Seu canibalismo também não é só uma espécie exótica de apetite. Sua fala é rascante porque nos dá o negativo da beleza do humano, sua matéria amorfa. Saber da sua história - e ter tido uma experiência no teatro com ela - não nos permite olhar a nudez botticelliana sem a imagem do seu negativo, corroborando a tese de Didi-Huberman (1999) de que não há imagem do corpo sem a visualização de sua abertura.

A nudez da Vênus de Botticelli pode parecer impenetrável, uma nudez de arte, desencarnada, um conceito: o que se toma como a beleza da nudez feminina é a imagem de uma superfície lacrada e sem carne. A nudez feminina na arte clássica é sempre fechada. Sua representação só é considerada bela quando não há mucosa ou orifício aparentes. O sexo feminino aberto é um escândalo, uma afronta. Representá-lo é uma desmedida. Logo no início do espetáculo, Liddell oferece sua nudez aberta, como uma carta de intenções. Sua arte tem carne, sangue, orifícios, muco. É, portanto, penetrável. Para tratar da beleza, a obra quer o negativo da beleza, o canibalismo, a necrofilia, a violência. A carne da sua arte não é lisa e pura. Ao abrir o sexo e falar na primeira pessoa, ela expõe a sua carne, a sua violência, a sua necrofilia, o seu canibalismo.

Com esse gesto, a peça tangencia um ponto crucial do debate sobre a violência contra a mulher - a cultura cotidiana de depreciação do órgão sexual feminino. A cultura burguesa e a noção geral de arte têm pavor das aberturas. E o sexo feminino é, acima de tudo, abertura. Ele contém a beleza apolínea e a violência dionisíaca ao mesmo tempo, a dialética entre a forma e o disforme. Não se trata de uma imagem simples.

Didi-Huberman apresenta a ideia de que para Bataille a nudez é um traço ontológico fundamental porque abre o nosso mundo. A nudez não seria uma imagem definitiva, mas sempre um processo, um deslizamento, que se furta à representação porque põe o ser em movimento:

Elle fait du glissement lui-même une dynamique d'exubérance ontologique, une dynamique d'ouverture que la représentation échouera généralement à « distinguer. » La nudité est la chose du monde la moins définie pour la raison essentielle qu'elle ouvre notre monde. (Didi-Huberman, 1999: 95) 
Essa dialética da beleza pressupõe tanto a crueldade do desejo de abrir, a vontade da transgressão da integridade da carne, quanto o desejo de permanência, de fazer durar. Na narrativa de Sagawa, o momento em que ele se depara com o útero no cadáver desmembrado de Hartevelt e por um instante lamenta é exemplar desse movimento. O modo como o espetáculo põe em cena tamanho horror, sem julgamento, é desconcertante.

Se considerarmos, com Didi-Huberman e Bataille, que a nudez é um traço ontológico fundamental, talvez faça sentido dizer que a nudez nas peças de Liddell é um traço ontológico fundamental da sua noção de arte, que trabalha sobre a beleza, mas a entrelaça de crueldade e horror. A integridade da arte enquanto organismo social estabelecido, enquanto corpo burguês de alta cultura, é trespassada com essa abertura para o disforme. Essa operação é prenunciada no seu corpo, mas se expande de maneira hiperbólica para os corpos das jovens do coro botticelliano, que se transfiguram em uma impressionante coreografia de erotismo, força e crueldade. Acontece um deslizamento da arte para dentro de si, para uma noção de arte que sempre precisa ser reaberta, na qual irrompem os sintomas do humano a que comumente nos referimos como inumanos.

Com essas operações de abertura, não são apenas as ideias de arte e beleza que se problematizam. A Paris que aparece em ¿Que haré yo con esta espada? não é a do Louvre, não é uma Paris de paisagem e mármore esculpido. É uma Paris depois da queda, de carne e ossos à mostra, com sangue escorrendo pelas ruas. Mas, afinal, não foi sempre sangrenta a imagem de Paris? A palavra terror não esteve sempre marcada na sua história, com sua grande revolução e sua famosa guilhotina? Não ouvimos no hino da França o clamor «Qu'un sang impur abreuve nos sillons»?

\footnotetext{
REFERÊNCIAS BIBLIOGRÁFICAS

CORnAgo, Óscar, «Atra Bilis o el rito de la perversión». In Archivo virtual de Artes Escénicas. Disponível em http://artesescenicas.uclm.es/index.php?sec=texto\&id=25http://artesescenicas.uclm.es/index. php?sec=texto\&id $=25$.

DIDI-Hu BER MAN, Georges (1999), Ouvrir Vénus: Nudité, rêve, cruauté, Paris, Éditions Gallimard.
} 